\title{
Digital Identity of Researchers and Their Personal Learning Network
}

\author{
Nuno Ricardo Oliveira and Lina Morgado \\ Laboratório de Educação a Distância e eLearning , \\ Universidade Aberta, Lisboa, Portugal \\ nrloliveira@gmail.com, Lina.Morgado@uab.pt
}

\begin{abstract}
In a networked society, everyday experience is shared in networks at a personal, professional and academic level. Thus, there is a need to have digital literacy skills to obtain and produce contents in a collaborative way, sharing the knowledge acquired in the personal learning network.

This paper is a reflection of literature revision in the $\mathrm{PhD}$ project of Online Distance Education and e-learning, concerning themes such as digital identity and personal learning networks. In this way we aim to make a literature analysis about the necessity of digital literacy so that we may obtain competencies for a personal learning network.
\end{abstract}

Keywords: collaborative learning, Digital Identity, Digital literacy, personal learning network, skills.

\section{Introduction}

The appearance of emerging digital environments and pedagogies has enabled the introduction and adoption of new practices and behaviours of individuals in a university academic context. It is also in this context that the Web 2.0 has an increasing use by academic community - teachers, students and researchers - to create, stimulate and expand learning in an informal way, even when knowledge is acquired in a formal context. It is also in this background that we situate the importance of a digital literacy to improve the digital identity by members of academic communities, that enables, among other things, the creation of social connection networks (teachers, researchers, students or experts, etc.), which, in the perspective of Rodrigues \& Beefun [1], are very important for an open and collaborative learning in the network.

The Web 2.0 encourages sharing, disclosure, collaboration and cooperation, making the web social and participatory whilst also an integrating part of a social platform and on a network, where each one can share their contents through the various applications, such as: blogs, forums, social networks, wikis, amongst others. They update and share information easily, creating personal learning networks, the user being the main mentor of the nodes of their personal network.

This article results in a literature review for the of a $\mathrm{PhD}$ thesis that looks at the questions related with the problematic area that presently constitutes in the Digital 
Identity of an Online Distance Education and e-learning researcher, and their personal learning environment to study the genesis, management and dynamics of their Personal Learning Network (PLN). In this perspective, Digital Literacy is a patent parameter and important to analyze the reality of the community of researchers, studying on this project.

Therefore, the study looks to contribute to the comprehension that as of how a community of researchers construct, keep and make dynamic their Personal Learning Network (PLN) so as to make the most of collaborative and shared knowledge. By means of this process we understand the importance of the researcher to having digital literacy so as to promote a digital identity.

\section{Emerging Digital Environments and Pedagogies}

With the evolution of Internet, Web 2.0 is acknowledged as a platform of creation, sharing and constantly modifying contents, being user-centered, allowing both for interaction and communication as well as the creation of networks. According to some authors, among them Solomon and Schrum [2], this evolutionary phenomenon has altered some fundamental aspects on how individuals act and behave on the network: how they link within themselves, interact and share information, purchase, socialize, learn and work.

In this framework, the surging and growing of emerging digital environments is constant, defining new practices and behaviour of individuals. It is also in this context, that we note that the Web 2.0 is used more steadily by the academic community, teachers, students and researchers, to create and expand learning in an informal way, even when knowledge is acquired in a formal context.

The importance of a digital literacy and digital identity by the members of the community, allows among other actions, creations of very important social connection networks (teachers, researchers, students or specialists, etc.) in the perspective of Rodrigues \& Beefun [1], for a collaborative learning on an open network.

Users make use of these networks and/or virtual learning communities in order to share information and knowledge in their area of interest, research or learning. According to Dias [3], the immersion of digital environments in an educational perspective can promote and sustain the development of open pedagogies, with evidence for interactions between the group members, those of collaborative nature standing out in a social network context [3], a digital literacy being necessary. Also Morgado [4] makes a perspective of the creation of virtual communities where personalization and openness are defining characteristics and in which, whether by the sharing of contents and experiences, or by the dynamics of interaction, follow the main open access allowing a collaborative open learning, designating a networked class. In turn, Keats \& Schmidt [5] argue that, among the changes that have occurred in recent years with impact (both in technological, or educational terms), the greatest importance is attributed to the role of students as creators of shared knowledge, being that social networks play an important role in the process of collaborative open learning. The correct use of digital media is an asset for collaborative learning through a network of social connections [6]. 
Dias [3] states that the opening of formal learning spaces for social interaction of the web represents the possibility of members of traditional communities to participate in new cultural activities, using the potential of digital technologies to create networks of social interaction and collaborative learning. This then allows a new design and experience of learning scenarios and knowledge.

However, all these existing and emerging phenomena, as well as emerging pedagogies [7] lead us to convene for this discussion the issue of a digital literacy with the latest information which is fundamental while the facilitator is in the learning process, through social and collaborative interactions, not forgetting the critical insight needed to select what are important and meaningful contributions to the network.

Digital literacy is a concept of a recent and extensive diversity of views and interpretations. For Ala-Mutka, Punie \& Redecker [8], Martin [9] and Goodfellow [10], digital literacy is the domain of tools and encourages the use of technology in the context of educational oriented digital skills promoting an awareness of criticism in the content created and used. On the other hand, it implies the effective use of technology in multiple digital formats, from a variety of sources and devices - computer, tablet or smartphone, etc., to obtain information or knowledge.

"Having digital literacy requires more than just the ability to use software or to operate a digital device it includes a large variety of complex skills(...) A conceptual model that was recently described by the authors suggests that digital literacy comprises five major digital skills: photo-visual skills ("reading" instructions from graphical displays), reproduction skills (utilizing digital reproduction to create new, meaningful materials from preexisting ones), branching skills (constructing knowledge from non-linear, hypertextual navigation), information skills (evaluating the quality and validity of information), and socio-emotional skills (understanding the "rules" that prevail in cyberspace and applying this understanding in online cyberspace communication)" [11].

Therefore, taking into account the specialized literature, digital literacy may include: (a) social practices - supported by skills, strategies and an attitude that encourages and supports the capacity of an individual to represent and understand the various ideas using digital tools [9],[12], (b) the use of technologies in a creative form - the use of tools to meet the personal and professional individual's needs [9],[13], (c) adequate knowledge to undertake the management of public and private digital spaces that enable the construction of an identity that reflects the profile and career of individuals in an academic, professional and personal level [4], [14], [15].

\section{Digital Identity}

The digital dimension of identity is understood as the total information about the individual, from credentials that allow access to the closed system, to the representation of the complex "I" in an open digital space [16]. In this sense, there is a tendency to optimize learning with the use of digital technologies available to the individual and through the network. With this development, there is an awareness of the need to 
promote new forms of learning, collaboration and dissemination of work as part of a digital brand, both at a personal and academic and professional level [14].

The digital presence of an individual is no longer a process that depends only on him, but also on the individuals who compose the network, whether they belong or simply have access to the information. Thus, the individual must know how to manage their presence in public and private online spaces [17], [18], being one more of the skills acquired by digital literacy.

For Williams, Fleming, \& Parslow [19], the concept of Digital Identity (ID) is relatively recent and derives from the practices that individuals have been developing on the network. It is therefore an important element because it is the reflection of the personal, academic and professional life of the individual. According to research by Aresta [15] carried out in a case study with university students, two profiles of digital identity emerged: student awareness about their own digital identity and their reputation whilst a student and professional.

In turn, Costa \& Torres [14] also highlight two major areas in which the ID is focused: presentation and reputation. At first the authors report that the ID deals with how individuals work online and how they engage and interact in shared spaces, i.e. their profile whilst online. The second focuses on the perspective that others have of the individual, i.e. what others think about your "I". To Warburton [16], the ID already allows the building of trust and also contributes to the reputation, and the persistence in maintaining credibility, a fundamental feature to obtain a relevant reputation.

White [20] refers to two perspectives of the representation of the "I" in the digital space - the visitor and resident. The visitor is one that will create different identities, so as not to bind to any in particular while the resident identity, however, feels the need and desire to build a strong and consistent identity, establishing through this the foundation for a network of "prestige contacts." Through this network, the individual reveals experiences, skills and capabilities on how to communicate, interact and share the online space.

Aresta [15] states that digital identity works in a sense better than a curriculum vitae, as it reveals to "friends" and/or to public in general, according to the notions of the privacy of the profile, a personal, educational and professional background.

Warburton [16], in turn, states that the ID reflects on the different aspects of the individual's personality depending on the context, be it professional (researcher, lecturer, teacher, etc.) or private (personal relationships), the attitudes, behaviour and sharing made differently. Thus, our digital identity, as well as our own personality, is constantly changing and is mirrored in the environments in which we coexist online, be it on those in which we have permanent access, those that are irregular or even those that we simply created a profile to view and test its usefulness both on a private or professional level, i.e., a fragmented ID, consisting of various services and networks scattered around the Web in which we are present and/or in which we participate on a personal, academic or professional level. For some authors such as Margaryan, Nicol, Littlejohn, \& Trinder [21] and Warburton [16], nowadays, with the evolution of the Internet and the importance given to the social web, the existence of an identity online on a network is an impossible phenomenon to contour. The 
knowledge and the capacity of researching, evaluating, creating, sharing information and synthesizing have become more and more important.

The social Web is characterized by media coverage and individual participation in various spaces and emerging environments through sharing, recording on databases (whether banking, institutional or social networking), blogs or discussion forums, allowing the construction of a digital identity network [16]. In an educational context, social software applications consist in providing the level of communication and interaction between individuals and/or groups, promoting the production of knowledge and sharing with the community [22]. This action enables a digital literacy, because the higher the share (of information), the more likely the individual will have to learn and acquire new knowledge.

\section{Personal Learning Network}

The technological evolution creates new challenges for education and research, as we nowadays live in a network. The network is comprised of individuals who are part of our everyday lives that share interests, resources, thoughts, links, insights and jokes, among many other things, but the key is that they enrich our professional and personal life [23].

In an interesting analysis of what he termed as digital scholarship, Weller [23] compares the use of the tools he used as a researcher and those he uses currently: the books - were accessed via library e-books and audiobook; magazines - through two online databases: Google Scholar and Mendeley; Delicious/social bookmarking, blogs, YouTube, Wikipedia, Slideshare, Scribd, Cloudworks, Twitter, personal networking, conferences and seminars. The individuals of an open digital world are defined less by the institutions to which they belong to and more through the network and digital identity they establish.

Therefore, the characteristics of Web 2.0, that motivate and facilitate the proliferation of tools that allow you to create, edit, simulate, comment, share, text, sound, image and video are great tools to give value to Personal Learning Environments (PLEs) and a motive for networked learning [24] allowing a collaborative and open social learning through Personal Learning Network (PLN).

Both the PLE and PLN are based conceptually on Siemens and Downes connectivism. The fundamental premise of connectivism is the binding of the individual through us (the connection points, which bring content or facilitate interaction) within a network, and that subsequently produce knowledge through the established connections [25], [26], [27]. Knowledge is, for these authors literally formed by the set of actions and experiences. This implies a pedagogy that (a) seeks to describe networks of success - identifying their properties, described by Downes [25] as diversity, autonomy, transparency and connectivity, and (b) seeks to describe the practices that lead to these networks, both in the individual as in the society - characterized as adapted practices of demonstration (by teacher), and practice and reflection (by student). According to connectivism a) learning occurs like a process in a distributed network, based on recognition and interpretation of patterns b) the learning process is 
influenced by the diversity of the network, i.e. the strength of the bonds c) the memory comprises of adapted patterns of connectivity of the actual state d) the transfer occurs through a process of connection and, e) the best for complex learning are learning domains in permanent change [25], [28].

In short, Connectivism presents a model of learning that acknowledges the great changes in society where learning is no longer seen as an individual activity. When new tools are used, people work and operate differently. In education, the recognition of these new learning tools has happened in a very slow manner. In this sense, connectivism provides insight into competencies and tasks required for students to grow and adapt to a digital age of knowledge [29].

Learning in this perspective, happens through practice, dialogue and interaction with others on networks that are themselves connected, interactive and open channeled, allowing each student to build their learning space, focusing on their interests and needs.

According to the first comprehensive review of the concept of PLE performed by Mota [24] there are several definitions given by various authors, some of which we refer to: Lubensky [30] defines PLE as centered on the ease for an individual to perform actions such as access and aggregation of digital artifacts in their learning experiences. Siemens [7] also refers to a collection of tools coupled through openness, interoperability and student control. Mota [24] highlights the vision of Anderson [31] on PLE, because such enhances and leverages the input of the learner; protects and values identity; respects academic property, is focused on the Internet, supports multiple levels of socialization, administration and learning; supports communities of inquiry between and within subjects, programs, institutions and individual learning contexts.

With the evolution of social software and conceptual discussion around PLEs, changes are found that intend to reflect on emerging pedagogies that result from digital environments and emerging technologies. For example, Schaffert \& Hilzensauer [32] on reflecting this connection, identified seven aspects where there are changes in learning supported by PLE: 1) the role of the individual as active content creator, 2) personalization, with support from the community, 3) learning content as unlimited space, 4) the significant role of social participation; 5) ownership of individual data; 6) self-organized learning for the culture of schools and organizations, and finally 7) the use of social software tools and aggregating content from multiple sources.

For Castañeda \& Adell [33], PLE consists of 3 dimensions and interoperable tools: 1) tools and strategies for reading, in that the sources that are accessed provide certain information in the form of object or artifact; 2) tools and strategies for reflection this refers to space environments or services that can transform information (places to write, review, analyze, recreate and post); and finally, 3) tools and strategies regarding: the environments where there is a relationship with others and learning is made.

The third dimension- Personal Learning Network (PLN) - is a relatively recent concept, justifying thus that scientific production is still low. That is also why it is often confused with the concept of Personal Learning Environment (PLE).

The PLN is defined by the set of connections between individuals, with the objective of enhancing mutual learning through feedback, ideas, documentation, new 
contacts, in order to obtain a network of learning and acquiring new knowledge. It is a network of people with whom you are connected to in order to learn and that is created according to personal interests and needs, providing learning opportunities, providing answers to questions and contributing to mutual learning. Having defined its conceptual contours, it interests us at this moment to understand how to build a PLN. According to Digenti [34] firstly it is important to understand the role of individuals on the network, as a reciprocal relationship is created. In this perspective, each individual member of the network should be concerned with providing information representing an added value in the learning process of the other members.

In the era of experience in network, in which we are connected to the internet almost 24 hours a day, we have the opportunity and the challenge of being able to have a lump sum of human knowledge and billions of prospective teachers "with just one click," through informal learning. The PLNs of each individual allow us to have access to this reality, which, according to Richardson [35], is not difficult to build. This author proposes six steps to build a PLN and maintains that its value is the commitment and the maintenance of the interactions created.

From an analysis of learning networks, Downes [36] listed four properties that define a learning network:

1. Diversity - allows you to have multiple perspectives, enabling to "see things" from a different point of view, due to the heterogeneity of the elements that make up the network;

2. Autonomy - each individual acts independently with respect to their network and through social software and content creation tools (blogs, etc.);

3. Interactivity and connectivity - should be a reality in the individual links, in order to obtain knowledge produced from the activity performed in the network, in other words, through dialogue and interaction between members of the network;

4. Opening - each network entity should be able to contribute to and receive from the network. This openness is what allows interactivity between individuals and that allows students to have learning outside the classroom and share that learning with the world.

Although the web can itself be constituted as a learning platform in the sense given by Downes [36] and Mota [24], the learning environment is dependent on the relations established between individuals. The effectiveness of the web is on the opportunities it offers to individuals in forming themselves as creators of knowledge (rather than mere collectors). Despite web tools providing a space for interaction, its added value is the ability to leverage an environment of effective and interactive learning [37]. Flexibility and adaptability is the key to lifelong learning in a networked society, as well as opportunities for personalized learning [38].

Each individual, in an attempt to create connections with other people with similar interests, create their own PLN. The links grow by the dialectic of providing and acquiring relevant information and personal perspectives on topics that are important to the particular individual, but also to give something to others through Web 2.0 tools [39]. The practice of cultivating an online PLN contributes to the emancipation of the individual as well as to demonstrate their skills in digital literacy. 
The PLN, in the opinion of Rajagopal et al. [40], is a network created by an individual specifically in the context of their professional activities through online platforms in order to support their needs in learning. So when a professional intentionally creates, maintains and activates their strong, weak and very weak links to contacts in your network, whether personal or professional contacts, the purpose is to improve their learning, using technology. Thus we are faced with creating a Personal Learning Network. In this perspective, the student at the network core organizes the whole environment, navigation, selects and chooses the most relevant sources of information [32], [41], [42], but this requires the student to have a high level of control over the tools used.

The technologies included in PLN allow students to use, modify and adapt their network to meet their learning needs [38]. But technology does not yet support the distinction of the degree of bonding (strong, weak or very weak), but provides a common platform where people can connect (social networks like LinkedIn, Facebook, Twitter, online conferences, workshops and Webinar platforms). It is yet important to stress that in face to face events, there is support for web-based technologies, thus allowing the possibility of creating valuable connections in the future.

According to Lalonde [43] building a PLN can be very personal and intimate, involving the negotiation of social relations with the goal of learning. In this sense, it is up to the individual to decide what to include in their PLN. Digenti [34] had already mentioned this fact when referring to collaborative learning, in which he stated that members should develop awareness on how to create strong networks among current and former members.

Rajagopal, Verjans, Costa, \& Sloep [44] stress the importance of the issue of PLN in recent studies, due to the generalization of the theme itself, because the effective use of learning resources as PLNs depends on the knowledge of contacts that each individual is linked to. Students support their networking needs of informal learning through their links with other people and resources, often supported by information and communication technologies. These skills are related to the content, such as being able to engage in conversations and being able to communicate ideas, thoughts and opinions to a listener [45], [46] but also in relation to knowledge in building their own network and continuously maintaining and enabling PLN [47], in particular to be able to identify the experience and knowledge of the connections in PLN [40].

With the expertise to develop these skills, students will be able to build effective and valuable personal learning networks to support their learning needs in the present and future. Thus, it is important for individuals to realize that the experience and knowledge of individual contacts can benefit their learning [48].

In short, the main elements that characterize the relations developed between members of the network are reciprocity and trust, encouraging the exchange of information with the goal of learning. PLNs describe the habits of informal learning and create learning opportunities through relationships and interactions. They are not social networks, as the incentives to participate in them are learning. They are referred to as an environment of autonomous learning in social knowledge and contacts created on the network. Each individual in this whole network serves the personal learning needs, which is not limited by collective goals. 


\section{Conclusion}

In the digital era in which individuals live in a social web and that Personal Learning Networks are constructed, it is fundamental to talk about the competencies for the construction of those networks. The proposal of this paper was to analyze how digital literacy allowed the creation, dynamics and maintenance of a Personal Learning Network of a community of researchers.

Throughout the article we analyzed and explored diverse authors that demonstrated the necessity of a digital literacy for the promotion and experience of a PLN, being that these competencies do not deplete in digital literacy.

To sum up, the Web 2.0 promotes the sharing, collaboration and cooperation, turning into a social platform and network, where each one shares their contents and acquires knowledge through sharing contacts that make up their PLN. Through this process we demonstrated the importance of researchers acquiring competencies of digital literacy in order to promote a digital identity of their PLN.

\section{References}

1. Rodrigues, M., Beefun, H.: A aprendizagem social, via web 2.0, na educação e formação. In: Actas do II Congresso Internacional TIC e Educação, Lisboa, December 2, pp. 10521058 (2012), http: / / ticeduca.ie.ul.pt/atas/pdf/221.pdf (retrieved November 01, 2013)

2. Solomon, G., Schrum, L.: Web 2.0 New Tools, New Schools. ISTE (Internet Soc. Tech. Educ.), Washington, DC (2007), http: / / books.google.pt / books? id=ZKKQMLir_mMC\&printsec=front cover\&hl=pt PT\&source=gbs_ge_summary_r\&cad $=0 \# \mathrm{~V}=$ onepage\&q\& $\mathrm{f}=\mathrm{fal}$ se (retrieved)

3. Dias, P.: Comunidades de educação e inovação na sociedade digital. Educação, Formação \& Tecnologias 5(2), 3-9 (2012)

4. Morgado, L.: The networked class. In: Wankel, C. (ed.) Cutting-edge Technologies in Higher Education. Educating Educators with Social Media, vol. 1, pp. 135-152. Emerald Group Publishing, Bingley (2011)

5. Keats, D., Schmidt, J.P.: The genesis and emergence of Education 3.0 in higher education and its potential for Africa. First Monday 12(3) (2007)

6. Castells, M.: La galaxia Internet, p. 302. Areté, Barcelona (2001)

7. Siemens, G.: PLEs - I Acronym, Therefore I Exist. Elearnspace2 (2007) (retrieved September 30, 2013)

8. Ala-Mutka, K., Punie, Y, Redecker, C.: Digital Competence for Lifelong Learning. Institute for Prospective Technological Studies (IPTS), European Commission, Joint Research Centre, Seville (2008), http://ftp.jrc.es/EURdoc/JRC48708.TN.pdf (retrieved)

9. Martin, A.: Digital Literacy and the "Digital Society". In: Lankshear\&, C., Knobel, M. (eds.) Digital Literacies: Concepts, Policies and Practices. Peter Lang, New York (2008)

10. Goodfellow, R.: Literacy, literacies, and the digital in higher education. Teaching in Higher Education 16(1), 131-144 (2011)

11. Eshet-Alkali, Y., Amichai-Hamburger, Y.: Experiments in digital literacy. Cyberpsychology \& Behavior: The Impact of the Internet, Multimedia and Virtual Reality on Behavior and Society 7(4), 421-429 (2004) 
12. McLoughlin, C.: What ICT-related skills and capabilities should be considered central to the definition of digital literacy? In: Bastiaens, T., Ebner, M. (eds.) World Conference on Educational Multimedia, Hypermedia and Telecommunications (EDMEDIA 2011), vol. 2011, pp. 471-475. EdITLib, the Digital Library for Education \& Information Technology (2011)

13. Bawden, D.: Origins and Concepts of Digital Literacy. In: Lankshear, C., Knobel, M. (eds.) Digital Literacies: Concepts, Policies and Practices, pp. 17-32. Peter Lang, New York (2008)

14. Costa, C., Torres, R.: To be or not to be, the importance of Digital Identity in the networked society. Educação, Formação \& Tecnologias, 47-53 (April 2011)

15. Aresta, M.S.L.: A construção da identidade em ambientes digitais: estudo de caso sobre a construção da identidade online no Sapo Campus e em ambientes informais. Dissertação de Doutoramento. Universidade de Aveiro, Portugal (2013)

16. Warburton, S.: Digital identity matters. Journal of the American Society for Information Science and Technology 56 (2010)

17. Cranor, L.F., Reagle, J., Ackerman, M.S.: Beyond Concern: Understanding Net Users' Attitudes About Online Privacy. Cornell University Library. Computers and Society; Human-Computer Interaction (April 18, 1999)

18. Alexander, B.: Web 2. 0 and Emergent Multiliteracies. Theory Into Practice 47(2), 150160 (2008)

19. Williams, S., Fleming, S., Parslow, P.: This Is Me - Digital Identity for careers. CentAUR: Central Archive at the University of Reading. Lulu, Reading (2010)

20. White, D.: Not "Natives" \& "Immigrants" but "Visitors" \& "Residents." TALL blog. Online education with the University of Oxford (2008),

http: / / tallblog. conted.ox.ac.uk/index.php/2008/07/23/not-

natives-immigrants-but-visitors-residents/ (retrieved October 10, 2013)

21. Margaryan, A., Nicol, D., Littlejohn, A., Trinder, K.: Students' use of technologies to support formal and informal learning. In: Luca, J., Weippl, E. (eds.) Proceedings of World Conference on Educational Multimedia, Hypermedia and Telecommunications 2008, vol. 2008, pp. 4257-4266. AACE, Chesapeake (2008)

22. Jorge, N., Morgado, L.: Contextos de aprendizagem 2.0: a utilização de ferramentas Web 2.0 para uma aprendizagem em contexto. Revista Iberoamericana de Informática Educativa $12,3-13(2010)$

23. Weller, M.: The Digital Scholar: How Technology Is Transforming Scholarly Practice. Bloomsbury Academic (2011), doi: http: / /dx.doi.org/10.5040/9781849666275

24. Mota, J.: Personal Learning Environments: Contributos para uma discussão do conceito. Educação, Formação \& Tecnologias 2(2), 5-21 (2009)

25. Downes, S.: Connectivism and Connective Knowledge Essays on meaning and learning networks. National Research Council, Canada (2012)

26. Siemens, G.: Connectivism. Connectivism (2012), http: / / www. connectivism. ca/ ?cat=3 (retrieved October 01, 2013)

27. Morrison, D.: How to Create a Robust and Meaningful Personal Learning Network [PLN]. Online learning insights (2013), http: / / onlinelearninginsights.wordpress . com/ 2013/01/22/how-to-create-a-robust-and-meaningful-personallearning-network-pln/ (retrieved September 25, 2013)

28. Siemens, G.: Connectivism: Learning as Network-Creation. eLearnspace everything elearning (2005a), http: / / www. elearnspace.org/Articles/networks.htm (retrieved October 01, 2013) 
29. Siemens, G.: Connectivism: A Learning Theory for the Digital Age. International Journal of Instructional Technology and Distance Learning 2(1), 3-10 (2005b)

30. Lubensky, R.: The present and future of Personal Learning Environments (PLE). eLearning\& Deliberative Moments, (2006), http: / / www. deliberations . com.au /

$2006 / 12 /$ present-and-future-of-personal-learning.html (retrieved October 02, 2013)

31. Anderson, T.: On Groups, Networks and Collectives. Virtual Canuck (April 30, 2007), http: / / terrya.edublogs.org/2007/04/30/on-groups-networksand-collectives / (retrieved October 01, 2013)

32. Schaffert, S., Hilzensauer, W.: On the way towards Personal Learning Environments: Seven crucial aspects. eLearning Papers, pp. 1-11 (2008)

33. Castañeda, L., Adell, J. (eds.): Entornos Personales de Aprendizaje: claves para el ecosistema educativo enred. Marfil, Alcoy (2013)

34. Digenti, D.: Collaborative Learning: A Core Capability for Organizations in the New Economy. Reflections: The SoL Journal 1(2), 45-57 (1999)

35. Richardson, W.: Create Your PLN: 6 Easy Steps. Educational Leadership: Reflect, Refresh, Recharge 70, 20-22 (2013)

36. Downes, S.: Practice Learning Networks in Practice. Emerging Technologies for Learning 2 (2007)

37. Costa, C.: Lifelong learning in Web 2.0 environments. International Journal of Technology Enhanced Learning 2(3), 275-284 (2010), doi:10.1504/IJTEL.2010.033582

38. Costa, C., Keegan, H., Attwell, G.: Cartoon planet: Micro-reflection through digital cartoons - a case study on teaching and learning with young people. Romanian Journal of Pedagogy 7(9), 112-128 (2009)

39. Costa, C.: Educational Networking in the Digital Age. In: Thomas, M. (ed.) Digital Education: Opportunities for Social Collaboration, pp. 81-99. Palgrave Macmillan, UK (2011)

40. Rajagopal, K., Joosten-ten Brinke, D., Van Bruggen, J., Sloep, P.B.: Understanding personal learning networks: Their structure, content and the networking skills to optimally use them. First Monday 17(1), 1-12 (2012)

41. Wilson, S., Liber, O., Beauvoir, P., MIlligan, C., Johnson, M., Sharples, P.: Personal Learning Environments: Challenging the dominant design of educational systems (September 19, 2006), http: / / dspace.ou.nl/handle/1820/727 (retrieved)

42. Conole, G., Delaat, M., Dillon, T., Darby, J.: 'Disruptive technologies', 'pedagogical innovation': What's new? Findings from an in-depth study of students' use and perception of technology. Computers \& Education 50(2), 511-524 (2008)

43. Lalonde, C.: How important is Twitter in your Personal Learning Network? eLearn Magazine. Education and Technology in Perspective (2012)

44. Rajagopal, K., Verjans, S., Costa, C., Sloep, P.: People in Personal Learning Networks: Analysing their Characteristics and Identifying Suitable Tools. In: Hodgson, V., Jones, C., de Laat, M., McConnell, D., Ryberg, T., Sloep, P. (eds.) Proceedings of the 8th International Conference on Networked Learning 2012, Maastricht, The Netherlands, pp. 252259 (2012), http: / dspace.ou.nl/handle/1820/4224 (retrieved)

45. Kintsch, W., van Dijk, T.A.: Toward a model of text comprehension and production. Psychological Review 85(5), 363 (1978)

46. Dillenbourg, P.: What do you mean by "collaborative learning"? In: Dillenbourg, P. (ed.) Collaborative-learning: Cognitive and Computational Approaches, vol. 1, pp. 1-15. Elsevier, Oxford (1999)

47. Nardi, B.A., Whittaker, S., Schwarz, H.: It's not what you know, it's who you know: Work in the information age. First Monday 5(5) (2000)

48. Cigognini, M.E., Pettenati, M.C., Edirisingha, P.: Personal knowledge management skills in web 2.0-based learning. In: Lee, M.J.W., McLoughlin, C. (eds.) Web 2.0-Based ELearning: Applying Social Informatics for Tertiary Teaching, p. 109 (2011) 